\title{
Los costos de la migración desde Costa Rica*
}

Recibido: 30 de octubre 2016

Revisado: 7 de diciembre 2016

Aprobado: 26 de enero 2017

\section{Gustavo Adolfo Gatica} López

Guatemalteco, Licenciado en Teología, Máster en Economía del Desarrollo con énfasis en Gestión Macroeconómica. Investigador del Centro de Investigación en Cultura y

Desarrollo (CICDE) de la Universidad Estatal a Distancia (UNED). Investigador asociado del Instituto Centroamericano de Estudios Sociales y Desarrollo (INCEDES, Guatemala). Correo electrónico:

ggatica@uned.ac.cr / gustavoadolfogatica@yahoo

.com

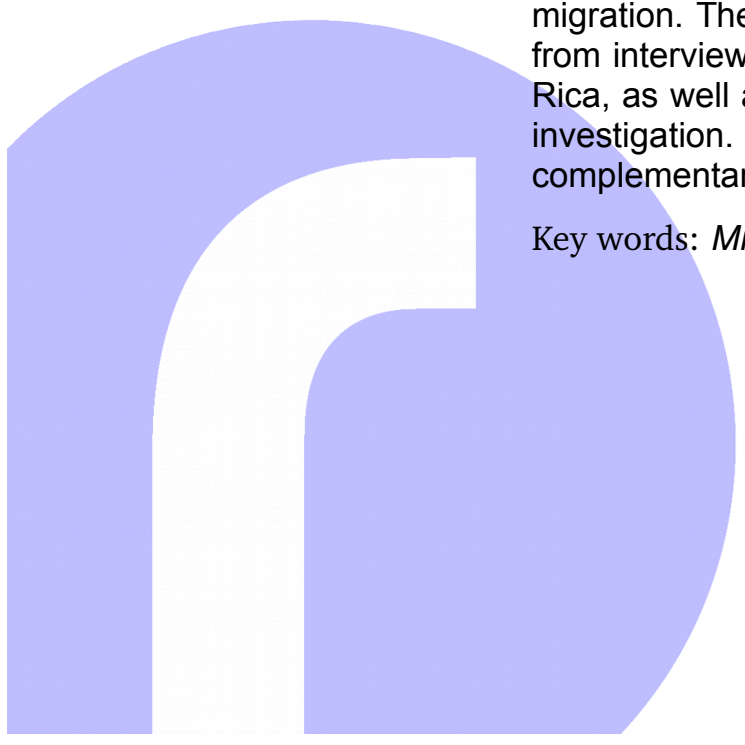

http://investiga.uned.ac.cr/rupturas/ (c) (i) (2)
Resumen: El presente artículo discute los costos asociados con la experiencia migratoria. Para ello, se lleva a cabo un repaso de los argumentos que con frecuencia se enarbolan para resaltar los beneficios de este fenómeno, en especial, las remesas familiares y su pretendido impacto en el desarrollo. Tomando como base entrevistas realizadas a hombres que emigraron y retornaron a su país de origen, se hace un análisis de algunos impactos que la migración tiene en la vida de las familias y en las comunidades de origen. A partir de este, se cuestiona la visión romántica que resalta solamente los aspectos positivos al tiempo que evita la revisión de los factores que siguen dando lugar a la migración. El artículo se nutre de información recolectada en trabajo de campo realizado a partir de entrevistas a personas costarricenses que migraron y retornaron a Costa Rica, así como de los resultados de una encuesta aplicada en el marco de una investigación más amplia. El empleo de ambas fuentes de información permite la complementariedad entre el uso de metodologías cualitativa y cuantitativa.

Palabras clave: ;Migración; migraciones de retorno; remesas familiares

\section{The Costs of Migration from Costa Rica}

Abstract: This article discusses the costs associated with migratory experience. To do this, a review is made of the arguments that are often raised to highlight the benefits of migration, especially family remittances and their alleged development impact. Based on interviews with men who emigrated and returned, an analysis is made of some of the impacts that migration has on the lives of families and communities of origin. From this analysis, a romantic view is challenged that highlights only positive aspects of migration, while avoiding a review of the factors that continue to lead to migration. The article is nourished by information collected in fieldwork made from interviews with Costa Rican people who migrated and returned to Costa Rica, as well as the results of a survey applied in the framework of a broader investigation. The use of both sources of information allows the complementarity between the use of qualitative and quantitative methodology.

Key words: Migration; return migration; family remittances 
*Este artículo es uno de los resultados del proyecto de investigación "Migraciones internacionales desde Costa Rica, aproximación a partir de dos estudios de caso en los cantones de Pérez Zeledón, Dota, Tarrazú y León Cortés", del CICDE y que fue coordinado por el autor del artículo.

\section{Introducción}

Diversos acontecimientos mundiales sucedidos en los últimos años han puesto en relieve los grandes éxodos humanos, los cuales frecuentemente han sido desplazados de la agenda de los medios de comunicación. En enero del año 2010, un potente terremoto devastó el centro de Haití y provocó más de 300000 personas muertas. Este evento hizo que miles de personas haitianas buscaran migrar hacia República Dominicana y hacia el territorio continental americano. El conflicto en Siria dejó más de 3,5 millones de personas refugiadas para finales del año 2015 expulsando a estas personas a países vecinos, europeos e incluso hacia el continente americano. Desde África Subsahariana, cada año, son miles de personas las que buscan llegar a Europa por medio de diversas rutas, lo cual convierte al mismo tiempo al Mar Mediterráneo en una peligrosa travesía.

La Organización Internacional para las Migraciones ha estimado que actualmente hay unos 232 millones de personas viviendo en países distintos al que nacieron (OIM 2015, 19). Los impactos de la migración no solo pueden medirse en la cantidad de personas expulsadas desde sus países, sino también en el número de los que pierden la vida en la travesía. Los costosos mecanismos de control de fronteras, de patrullajes terrestres y marítimos, para evitar que quienes se desplazan lleguen a las fronteras de los países de destino, no logran disuadir a aquellos con la legítima aspiración de buscar un lugar para reconstruir la vida que están intentando dejar atrás. En cambio, la obsesión de blindar las fronteras y controlar las rutas migratorias solo consigue incrementar los riesgos de quienes migran, incluyendo mujeres, niñas y niños.

Dentro de la literatura, se pueden identificar estudios y publicaciones que discuten las oportunidades que tendría la creciente tendencia migratoria hacia las ciudades (OIM 2015), o los beneficios de la migración como potencial catalizador y financiador del desarrollo (Orozco 2013; Orozco y Yansura 2013; Ratha y Plaza 2011; BID 2005). Estas investigaciones se abocan a resaltar los potenciales beneficios que tiene la migración tanto para los países de destino, como para los de origen, en este último caso, especialmente, a través de las remesas familiares.

Si bien se reconoce que las dinámicas migratorias pueden dar lugar a beneficios para las naciones de destino y las de origen, el interés de este trabajo es discutir acerca de los costos de estas tanto para las personas migrantes como para sus familias. ¿Por qué la atención en lo que denominamos los costos? Señalemos, de forma provisional, que entrevistas realizadas a hombres costarricenses que emigraron y retornaron muestran cómo la experiencia migratoria tuvo algunos costos que lograron identificar. Estos, con frecuencia, son invisibilizados en los relatos o análisis sobre las migraciones. 
Señalado lo anterior y sin perder de vista los impactos que la migración puede tener en los países de origen (como el despoblamiento, el desarraigo, la pérdida de recurso humano y de una parte del bono demográfico, por citar algunos), la atención se centrará en los impactos en la vida de hombres que han retornado a sus comunidades de origen y en una organización de reivindicación campesina de la que muchos de sus miembros han emigrado.

Dos interrogantes guiarán esta parte del trabajo: ¿cuál es el análisis e interpretación de los hombres que han retornado acerca de los costos de la experiencia migratoria? y ¿de qué forma el tejido social -expresado en una organización campesina- se ve alterado a partir de la emigración?

Este escrito se organiza en dos partes. En la primera, se hará un análisis desde la perspectiva de la economía política de los principales argumentos en torno a los beneficios (lo que denominamos discurso triunfalista sobre las migraciones) y los costos asociados a la migración. Se realiza una revisión de explicaciones más socorridas acerca cómo la migración y en especial las remesas familiares contribuyen al desarrollo. Se discuten tales planteamientos con el fin de evidenciar que en una región como Centroamérica deberían moderarse.

En la segunda parte y a partir del contexto de Costa Rica, se hará una aproximación analítica a partir de entrevistas realizadas a hombres que migraron y retornaron a este país; a familias con integrantes que han migrado, y a representantes de una organización campesina con una larga trayectoria en la reivindicación de los derechos de los agricultores, que ha existido por más de cuarenta años, en una región típicamente expulsora de migrantes en Costa Rica. Se identificó a las personas entrevistadas a través de la Unión de Productores Independientes y Actividades Varias (UPIAV), cuya sede se encuentra en el cantón de Pérez Zeledón, y con la cual se tiene una relación de colaboración y cooperación desde el Centro de Investigación en Cultura y Desarrollo (CICDE) de la Universidad Estatal a Distancia.

Para recolectar la información, se hicieron dos grupos focales y se les realizaron entrevistas a profundidad. La mayoría de los hombres participantes desplegaron su relato y testimonio resaltando los costos que tuvo la experiencia migratoria tanto en su vida personal y familiar como en el proceso de retorno al país. Hubo una constante en los relatos: destacaron que los beneficios económicos de la experiencia migratoria no compensan las rupturas familiares, la ausencia de los seres queridos o las pérdidas afectivas que se tuvieron. Durante las entrevistas reiteraron que una dimensión que suele quedar al margen acerca de lo que "se dice o cuentan" quienes emigran son los costos que tiene esta experiencia. Frente a esto, afirmaron que normalmente se destacan los logros o los relatos de éxito. Lo señalado por los entrevistados es de gran importancia en tanto que la valoración hecha de la experiencia vivida durante las entrevistas se planteó en términos dicotómicos: los costos-beneficios o ganancias-pérdidas de la migración. Lo anterior puede parecer un análisis reduccionista, sin embargo, representa la forma en la que los hombres entrevistados interpretan y dan significado a lo experimentado. 
Por otra parte, durante el diálogo con los participantes, se concluyó que el significado para ellos de la noción de "costo de la migración" correspondía al valor económico-material, afectivo y emocional que exige o tiene para cada uno este fenómeno, en este caso, lo que implica dejar la familia, la comunidad y el país.

Al poner título a este artículo, se recupera una de la valoraciones centrales llevada a cabo por quienes brindaron su testimonio. Si bien la experiencia migratoria es vista como una oportunidad con grandes beneficios, especialmente materiales, hubo consenso entre las personas entrevistadas en cuanto a que, en general, quienes migran y retornan mencionan muy poco los costos y los fracasos que asumieron o experimentaron. Frente a ello, se suelen resaltar las historias de éxito.

El contenido de las entrevistas y los relatos que se obtuvieron se ordenaron de acuerdo con las pérdidas más relevantes que las personas fueron mencionando: en relación con la familia (pérdidas afectivas), materiales y de vínculos con la comunidad. Esto fue denominado por los entrevistados "costos de la migración".

Este artículo forma parte de una investigación más amplia, la cual se ha dirigido a comprender y explicar los factores que intervienen en las migraciones internacionales desde Costa Rica en los últimos años. En otro artículo, se han expuesto los resultados de dos encuestas aplicadas a personas potenciales migrantes y a hogares con familiares en el extranjero que reciben remesas.

\section{Situando los argumentos triunfalistas acerca de la migración}

La migración suele suscitar discursos triunfalistas y con frecuencia se señalan algunos "beneficios" que genera. ¿A qué nos referimos con argumentos triunfalistas? Son aquellos que resaltan los "efectos positivos y los beneficios" de esta. Al poner su atención en estos efectos, se invisibilizan o minimizan el conjunto de factores que han y siguen causando desplazamientos y migraciones. Entre los aspectos positivos comúnmente destacados, están las remesas familiares, las cuales son asumidas como una fuente de recursos financieros para el desarrollo, y la transferencia de conocimientos y de capital humano calificado a partir del retorno de migrantes a sus países de origen. El carácter triunfalista que identificamos en estos discursos no se interesa en discutir las condiciones de salida en los países expulsores o los riesgos que enfrentan las personas migrantes en la travesía (por ejemplo la violencia, los secuestros o extorsiones) o; el blindaje de las fronteras de los países de destino. Tampoco toman en cuenta las restricciones a la movilidad humana derivadas de políticas migratorias elaboradas bajo criterios de Seguridad Nacional. Simplemente, dan por un hecho la existencia de migrantes en los países de destino, como si por un acto de magia hubiesen aparecido ahí. 
El carácter triunfalista que emerge en algunos discursos sobre migraciones y que resalta el papel de las remesas como fuente de financiamiento se encuentra, y parece ser muy conveniente, en organismos financieros internacionales. Esto porque en el pasado lideraron la aplicación de férreos programas de reformas (disminución) del Estado, promoviendo también reformas de mercado con mayor apertura al comercio internacional y; que enfatizaron en la contención del gasto público para lograr equilibrios fiscales. Hoy, como es el caso de Guatemala, Honduras y El Salvador, las remesas familiares triplican o quintuplican los flujos de inversión extranjera directa que reciben anualmente.

¿Quiénes promueven y dónde encontramos estos discursos? Son impulsados y están presentes en documentos elaborados por organismos financieros internacionales, como se verá más adelante. En estos estudios se sugiere que la migración tiene un "potencial" aporte positivo a través de las remesas familiares (BID 2005), recursos que, según esta lectura, tendrían que aprovecharse para el financiamiento para el desarrollo. Postulan que la migración es una variable independiente del desarrollo y que las remesas familiares son uno de los instrumentos que inciden positivamente en aquella (Orozco 2013; Orozco y Yansura 2013;; Ratha y Plaza 2011). Esta tesis también ha estado presente en Costa Rica. Céspedes, Monge y Vargas (2010) han sugerido que las remesas son "parte de la solución" y una "oportunidad para el desarrollo", también han señalado que "la migración ocurre en el Sur porque esa es la mejor decisión que toman los emigrantes en conjunto con su familia" (2010, 22-23).

¿Por qué resultan convincentes o convenientes este tipo de discursos? Hay al menos tres argumentos que se relacionan y potencian mutuamente, están referidos a los impactos positivos que se despliegan en tres escalas: global, nacional y local. Como se verá, la primera tiene un nivel de influencia decisivo en la configuración del imaginario acerca de las migraciones, al tiempo que puede alentar la formulación de políticas que favorezcan la expulsión de población migrante.

Los beneficios globales de la migración. Teniendo como telón de fondo los procesos globalizatorios, instituciones financieras multilaterales resaltan los beneficios de la migración, entre estos: el aumento del comercio, la inversión, y la transmisión del conocimiento y de tecnología que hacen las personas migrantes (World Bank 2016a, vii). Este mismo organismo reconoce que las remesas familiares equivalen a poco más de tres veces la ayuda oficial para el desarrollo y representan globalmente mucho más que los flujos de inversión extranjera directa -excluyendo la procedente de China-, con la particularidad de ser divisas con menor volatilidad que otros flujos financieros en la actualidad (2016a, 17) ${ }^{1}$.

Dada la importancia de las remesas familiares, organismos financieros multilaterales han desplegado iniciativas para mejorar el conocimiento de la economía migratoria, en particular de los mercados de remesas familiares. En América Latina y el Caribe, los estudios del Fondo Multilateral de Inversiones (FOMIN), que forman parte del grupo del Banco Interamericano de Desarrollo
1. Véase por ejemplo el documento de trabajo: Remesas a América Latina y el Caribe en 2011. Recuperando el crecimiento. Del Fondo Multilateral de Inversiones del BID. Disponible en: http://idbdocs.iadb.org/wsd ocs/getDocument.aspx?DOCNUM $=36723444$

También puede verse: Ratha y Plaza (2011). 
(BID), así como del Centro de Estudios Monetarios Latinoamericanos (CEMLA), dan cuenta de lo anteriormente afirmado. Algunas de esas investigaciones se han dirigido a identificar las oportunidades de inclusión financiera de los hogares receptores, así como a establecer el potencial de acrecentar los "beneficios de esos recursos" (Bonilla 2016, 2015).

El interés de estos trabajos por "conocer mejor el mercado de las remesas" se enfila en una doble dirección: "facilita que las autoridades de los países de origen de los migrantes puedan acercarse de mejor manera a sus connacionales, y... favorece que los distintos oferentes de servicios de remesas puedan acceder a los remitentes de remesas, para ofrecerles una variedad de servicios adicionales ya sea directamente a ellos o a las personas receptoras de esos recursos" (Bonilla 2016, ii; 2015, ii). Resulta llamativo que uno de los propósitos se dirija hacia los servicios de las empresas financieras que brindan el servicio de transferir remesas familiares, empresas que como es sabido, obtienen cuantiosas ganancias por la intermediación financiera que realizan.

También debe resaltarse que a nivel global se afirma que las remesas familiares son esenciales para mejorar las condiciones de millones de personas en los países en desarrollo (PNUD 2009, 80) y que cumplen una función ligada al desarrollo social (Orozco 2012, 68-76; Orozco y Yansura 2013). Lo paradójico de este argumento es que se transfiere la responsabilidad a las personas migrantes de ser "promotores de desarrollo" en sus países de origen.

Los beneficios de la migración en el plano nacional. Un segundo plano en el que se resaltan argumentos favor de la migración puede verse a escala nacional: la migración beneficia a los países tanto a los países de destino como a los expulsores. En el caso de los primeros, se ven favorecidos por contar con contingentes de personas trabajadoras que llegan en edad económicamente activa o de reproducción, sin que ello signifique ningún costo de formación ni capacitación para el lugar de destino, además, complementan o sustituyen la mano de obra local en actividades que los locales no quieren o no están dispuestos a asumir. En términos económicos, el PNUD (2009), estimó que "el crecimiento de la población debido a la migración aumenta el PIB real per cápita en el corto plazo, uno a uno, es decir, un $1 \%$ de crecimiento de la población debido a la migración aumenta el PIB real per cápita a corto plazo en un 1\%" $(2009,93)$.

En el caso de los países de origen, la expulsión de personas mitiga la presión sobre las estructuras socio-laborales locales (Orozco 2012, 211), dado que, al disminuirse la cantidad de personas en edad de trabajar, se reduce el número de demandantes de empleo.

Por otra parte, se argumenta que las divisas que llegan en forma de remesas familiares, pueden contribuir en términos macroeconómicos a disminuir el déficit de cuenta corriente en la balanza de pagos (como ocurre usualmente en países como El Salvador, Guatemala u Honduras) o contribuir a mantener el tipo de cambio relativamente apreciado, de acuerdo con el peso que tengan las remesas familiares en el Producto Interno Bruto Nacional. 
Los beneficios locales de la migración. Quizás, el nivel local sea el plano donde más se destacan los argumentos en torno a los beneficios de la migración. Se señala que la migración es una forma de mejorar las oportunidades de los miembros emprendedores de la comunidad. Se insiste en señalar que no migran las personas más pobres, sino quienes tienen iniciativa y algo que empeñar. Por otra parte, se señala que la migración permite la reunificación y el aprovechamiento de redes familiares cuando ya hay miembros (padres, madres, hermanos o hijos) que han migrado.

Al destacarse los beneficios de la migración en el plano local, también se resalta que permite la llegada de remesas, las cuales mejoran las condiciones de consumo de los hogares que las reciben (PNUD 2009, 82-85). En este sentido, además de tener un impacto macro, también se tiene un impacto microeconómico. Las experiencias de remesas comunitarias como las llevadas a cabo en el estado de Zacatecas en México (García Zamora 2001, 225-254; 2009, 337-360) o en algunos municipios de El Salvador, donde las personas migrantes reúnen estas para enviarlas a su lugar de origen y que sean utilizadas en alguna obra de solidaridad o de apoyo a su municipio, se presentan asimismo como experiencias beneficiosas de dicho fenómeno (PNUD 2005, 277).

¿Por qué resultan atractivos estos argumentos? Debido a que resaltan los efectos positivos de la migración en los planos citados, al tiempo que descartan al menos tres consideraciones básicas. La primera es la anulación del contexto desde el cual las personas son forzadas a migrar. Ello se sustituye por la decisión individual de quien lo hace, por lo tanto, el entorno es desdibujado y se le despoja de cualquier posibilidad de influencia. Dicho con otras palabras, el análisis se traslada a un ámbito privado, en el cual, "la decisión de migrar se toma en abstracto". En segundo lugar, al anular el contexto social, histórico o económico desde el cual las personas son expulsadas, se renuncia a discutir las causas centrales que propician estos desplazamientos. No es "la falta de desarrollo" la que produce las migraciones, sino son las migraciones y su correlato, las remesas familiares las que impactan en el desarrollo. En tercer lugar, no se incluyen de forma explícita los costos de esta realidad, tanto a nivel familiar, comunitario, social, cultural o económico. En las entrevistas, este último aspecto fue relevante en los relatos de las personas que emigraron y retornaron a Costa Rica.

Para los intereses de este artículo, únicamente se presentan de forma general tres líneas de argumentos en favor de la migración y que se despliegan en tres niveles distintos de análisis. El de las críticas a estos, lo hemos desarrollado desde la perspectiva de la economía política en otro artículo en proceso de publicación. A continuación, se revisará la fuerza de tales planteamientos. 


\section{¿Es posible sostener solamente argumentos triunfalistas?}

En la actualidad, la discusión acerca de las migraciones está lejos de ser concluyente. Se encuentran argumentos que permiten tomar distancia de aquellos encargados de resaltar los beneficios de la migración sobre los costos de esta para los países expulsores, para las comunidades desde donde salen las personas, para las familias o para las organizaciones de las cuales estas forman parte.

Se suele caer en la trampa de relacionar automáticamente la migración y el desarrollo con el tema de las remesas familiares, como si estas fueran la variable independiente con la cual se construye algún tipo de desarrollo (Gatica $2013,142)$. Esto resulta en una ficción que busca hacer depender de los flujos de remesas enviadas por las personas migrantes, los recursos y el financiamiento para "impulsar a nivel local el desarrollo" de los países de origen, a partir de las transferencias financieras. ¿Es posible mantener los argumentos triunfalistas acerca de los beneficios de la migración? Seguramente no, por las razones que se describirán a continuación.

En primer lugar, estos argumentos pueden ser presentados con un carácter técnico, revestidos de una aparente neutralidad que claramente no tienen. Pécoud $(2015,39)$ sugiere la existencia de un discurso internacional sobre la migración (DMI). En oposición este autor propone una "visión integral de los desafíos migratorios, en él se identifican tanto los problemas como las soluciones y, al mismo tiempo, se acredita una manera de encarar dichos desafíos fundada en la cooperación entre los gobiernos y la implicación de los organismos internacionales". Tal discurso está arropado en una retórica tecnocrática y apolítica que busca presentarse de forma neutral y técnica (Mansur Dias 2014, 561), con el fin de recomendar a los Estados de los países tanto receptores como expulsores, no solo políticas sino acciones para aprovechar los beneficios de la migración.

Este discurso técnico se queda en el plano de los medios. Al procurar analizar los efectos positivos de las migraciones y en particular de las remesas familiares, se omite discutir e interpretar las causas tanto pasadas como presentes de las migraciones internacionales o los contextos globales de acumulación capitalista. Estos últimos y la división internacional del trabajo dan lugar, por una parte, a la existencia de una reserva permanente de obreros, como, por otra, a la segmentación espacio-territorial del trabajo y de quienes lo llevan a cabo. Harvey (2004) ha señalado que "si existen excedentes de capital y de fuerza de trabajo dentro de un territorio determinado (como por ejemplo, un Estado-nación) que no pueden ser absorbidos internamente deben ser enviados a otro lugar a fin de encontrar un nuevo terreno para su realización rentable para no ser devaluados" (2004, 103-104).

Si siguiéramos al pie de la letra el planteamiento de Harvey, la realidad se mostraría más compleja de lo que parece, pues los mercados globales están lejos de ser perfectos e integrados, con lo cual, la movilidad de las personas 
trabajadoras se enfrenta a todo tipo de restricciones que en tiempos de "globalización" deberían ser la excepción y no la regla.

Por otra parte, este discurso técnico renuncia a discutir el impacto que tuvieron las medidas de ajuste, privatización y desmantelamiento de los frágiles Estados de bienestar impulsados desde finales de la década de los años setenta del siglo pasado. Recuérdese que estas fueron cercanas y -en muchos casos- simultáneas a las transiciones experimentadas por las economías de muchos países de América Latina: pasaron de estar basadas en el sector primario a actividades de los sectores secundarios y terciarios, y derivaron en una rápida descampesinización. Tales procesos no fueron acompañados de medidas eficaces de reconversión productiva. Esto generó una fuerte presión en los sectores que históricamente estuvieron vinculados a la agricultura como actividad principal, lo cual obligó a los trabajadores a desplazarse a otras actividades tanto económicas como laborales y, sobre todo, a entornos distintos de la comunidad de origen. También, estos discursos omiten discutir los impactos pasados y presentes de las agresivas estrategias de liberalización comercial, las cuales ponen a competir economías asimétricas, con características distintas, y niveles de productividad y de protección desiguales.

En segundo lugar, se introduce y utiliza una categoría de análisis deliberadamente empobrecida. La categoría central presente en esta lógica discursiva triunfalista es la de desarrollo, a la que se empobrece y se reduce o sustituye con las nociones progreso o crecimiento económico. Progreso se limita a la búsqueda del incremento en la producción de bienes y servicios. El crecimiento económico se asume desde una perspectiva técnico-económica y condición indispensable para el desarrollo. De Cambra (2009), señala a propósito de la noción de desarrollo que se:

... parte de una ingenua y acrítica -pero no por ello caren-

te de contenido ideológico- concepción de la expansión tecnológica como motor de un crecimiento que permitirá una mayor acumulación de riqueza que, a su vez, nos llevará al reino de la libertad. Está claro que el modelo a seguir, necesaria y universalmente, es el de los denominados países desarrollados, bajo la guía de una ciencia económica presuntamente avalorista y desinteresada que promete que, si se sigue un proceso gradual y ordenado, algún día el pastel será suficientemente grande como para que haya para todos, anteponiendo la eficiencia y posponiendo la equidad $(2009,5)$. 
Esta aparente neutralidad ideológica, pero también teórica-metodológica de la noción de desarrollo, en el contexto del análisis migratorio, requiere de recursos (en este caso de divisas en la forma de remesas familiares) para obtener progreso y desarrollo económico en los países expulsores de población migrante. En el plano ideológico, la categoría de desarrollo es clave dentro de una dinámica lineal, la cual postula la existencia de países que presentan realidades de "menor desarrollo" -por ende, menor progreso- que deben avanzar hacia condiciones donde hay mayor desarrollo. Gudynas (2012) ha dicho que durante mucho tiempo se consideró el subdesarrollo como una fase previa al desarrollo. Subyace aquí una elaboración discursiva, la cual se traduce en políticas, donde los países -con menor desarrollo- deben seguir una trayectoria lineal y específica -preferiblemente recomendada o sugerida por los países más desarrollados o instituciones de estos- que les permitirá aprovechar las lecciones aprendidas de aquellos que han alcanzado mayor desarrollo. Esta linealidad pone a los países desarrollados como modelos o paradigmas a seguir y emular.

Por otra parte, bajo este esquema, se requiere la existencia de una serie de variables exógenas (inversión extranjera directa; transferencia de tecnología; apertura de mercados y, por supuesto, ahorro externo, expresado bajo la forma de ahorro de los trabajadores migrantes). Este marco asume, entonces, las migraciones y su correlato, las remesas familiares, como una variable independiente del desarrollo. Así, las migraciones inciden en el desarrollo y no el desarrollo el que incide en las características, intensidad y duración de las migraciones. Mansur Dias (2014) propone que algunos de los conceptos presentes en las políticas, discusiones y prácticas de control en torno a las migraciones a nivel internacional están influidos por el aparato de instituciones que llevan a cabo proyectos financiados con recursos de los países desarrollados. Estos conceptos dan lugar a una nueva semántica sobre migraciones, donde hay una re-significación de nociones como derechos humanos, gobernanza o migración segura, que adquieren un carácter instrumental en función del control migratorio que impulsan los países que financian a aquellas instituciones.

Dicho lo anterior, se comprenderá que con facilidad surja y se justifique un discurso triunfalista acerca de la migración, el cual postula que esta es variable determinante del desarrollo. Pécoud lo plantea en los siguientes términos:

Las remesas y, más ampliamente, las relaciones entre migración y desarrollo constituyen el núcleo del discurso internacional sobre migraciones. Forman parte de una representación optimista de la migración en la que ésta favorece el desarrollo de los países de origen, responde a las necesidades de los países de destino (en términos de mercado laboral o de demografía en particular) y además 
permite a los migrantes mejorar su nivel de vida. Este objetivo (llamado triple win: todos ganan) permite federar los intereses de los Estados y otros actores, como el sector privado (que ve reconocida la demanda de mano de obra extranjera y la flexibilidad) y de lo que las instancias internacionales llaman, la sociedad civil, es decir, las ONG o las asociaciones que trabajan en favor de los derechos y bienestar de los migrantes $(2015,39)$.

Los planteamientos de tipo triunfalista buscan legitimar un análisis en el cual todos los actores ganan con la migración: los países receptores y expulsores, $y$, por supuesto, quien migra y su familia. Por otra parte, bajo tal argumento, se deja por fuera el conjunto de factores que están a la base de la expulsión de personas, muchos de los cuales son responsabilidad de los países de origen. En Costa Rica, este planteamiento ha sido sugerido por Céspedes, Monge y Vargas $(2010,22)$, quienes, como se indicó en páginas anteriores, consideran que las remesas son "parte de la solución" y una "oportunidad para el desarrollo".

Finalmente, los argumentos de los beneficios globales de la migración se muestran incompletos cuando se revisa desde una perspectiva alternativa la noción de desarrollo, la cual es convenientemente empobrecida desde la visión triunfalista de las migraciones.

En tercer lugar, el uso productivo de las remesas. Un argumento bastante extendido acerca de los beneficios de la migración-remesas y sus impactos en el desarrollo se relaciona con los "usos productivos" que se le dan a estas transferencias. Este argumento ubica a las personas migrantes como los sujetos y las remesas como el instrumento que apalanca el desarrollo (Delgado Wise y Márquez 2009, 49; Bakker 2007, 54).

La evidencia empírica no permite afirmar de forma contundente que este sea un mecanismo sólido de apalancamiento financiero para emprendimientos productivos de los hogares receptores de remesas. A pesar de estimarse que para el bienio 2016-2017 habrá una tasa de crecimiento de los flujos de remesas hacia los países en desarrollo en alrededor de un $4 \%$ (World Bank 2016 b, 8), que en muchos casos es superior al crecimiento de muchas economías nacionales, nada garantiza -ni debería serlo así- que estas remesas se destinen a "usos productivos".

Los hogares que reciben remesas las destinan a diferentes usos, la utilización en actividades productivas es aún modesta. En el caso de México, BoniIla (2016, 19), a partir de una encuesta aplicada a 12960 personas mexicanas migrantes que envían remesas a su país, encontró que solo el 8,4\% destina el dinero "para pagos relacionados con inmuebles (propiedad del remitente de la remesa o de sus familiares) o en negocios propios". Un estudio 
similar, llevado a cabo por este mismo autor, en República Dominicana indicó que el 4,7\% invierte lo que recibe en gastos de capital $(2015,22)$.

En el caso costarricense, la evidencia señala que los "usos productivos" que hacen los hogares receptores de remesas no ocupan un lugar central en la forma como emplean dichos ingresos. De acuerdo con una muestra realizada por el Banco Central (2015), solo un 3 \% de hogares utiliza estos ingresos para negocios. Por otra parte, una muestra aplicada en el marco de una investigación coordinada por el autor a 358 hogares receptores de remesas en cuatro cantones de Costa Rica (Pérez Zeledón, Tarrazú, Dota y León Cortés) indicó que el $4,75 \%$ de estos destina una parte de los ingresos a negocios o emprendimientos económicos.

La insistencia de sugerir que una parte de las remesas deba ser utilizada como capital inicial para emprender una iniciativa productiva parece ser expresión de un discurso ideológico, en el cual, los que fueron expulsados del país deben hacerse cargo de financiar la empresarialidad de quienes se quedaron. Así, de forma simultánea, se promueve un sentido de individualidad y se exime de responsabilidad a otros actores (públicos y privados) respecto a la creación de oportunidades, de generación de empleo o del fortalecimiento del sentido social de pertenencia de los habitantes.

Pécoud, citando a Bakewell (2008), hace notar que este tipo de argumentos refuerzan un discurso moralizador en el "que los migrantes tienen una responsabilidad particular ante su país de origen y que aquellos que gastan de manera inútil su dinero (consumiendo en lugar de invertir, por ejemplo) cometen una falta moral, un reproche que raramente se hace a los ciudadanos de los países desarrollados" $(2015,47)$.

Además de lo señalado, hay otros temas que el discurso triunfalista en torno a las migraciones parece tener dificultades en abordar. Veamos brevemente algunos de ellos.

- Los argumentos que resaltan los beneficios de la migración suelen desvincular este tema de los perniciosos efectos que las políticas comerciales e industriales de los países centrales o "desarrollados" tienen sobre las estructuras productivas y socio-laborales de los países periféricos. Un ejemplo es la contradicción de los efectos de los acuerdos comerciales que se negocian. Estos últimos dan estabilidad jurídica para la libertad de movimiento al capital financiero, permiten el libre flujo de mercancías y restringen el movimiento de personas. Más aún, en la implementación de los acuerdos comerciales, se establece la reducción o eliminación de los aranceles a las importaciones que suelen destruir parte de la estructura productiva local de los países más pequeños, pero también, "las medidas distorsionadoras del comercio de las naciones industrializadas desplazan las exportaciones agrícolas de los países en desarrollo" (Stiglitz y Charlton 2007, 87). Estos acuerdos de liberalización del comercio crean costos de ajuste, que son, ni más ni menos, el desplazamiento de trabajadores de un sector (o de un país a otro) en los procesos de reforma (Stiglitz 
y Charlton 2007, 227-239). Paradójicamente, se restringe el tránsito de personas trabajadoras y se impulsan tanto políticas como legislaciones que desestimulan, castigan y criminalizan la migración irregular.

- El estilo de desarrollo capitalista impulsado por los países centrales y por empresas transnacionales originarias de estos tiene como rasgo característico la acumulación por desposesión (Harvey 2004, 118). Para Sassen (2003), este tipo de desarrollo requiere condiciones flexibles de los países receptores (crecimiento del desempleo o cierre de empresas dedicadas al mercado local). Más aún, uno de los ejes en torno al cual el sistema capitalista se polariza es el acceso a los recursos naturales del planeta (Amin 2010, 18), que no solo se monopolizan, sino que se explotan con prácticas extractivistas y depredatorias, las cuales, al deteriorar el entorno, dan lugar a eventos naturales. En los últimos años, se han incrementado los desplazamientos humanos debido a los efectos del cambio climático y a desastres naturales. De forma irónica, estas prácticas crean destrucción y migraciones, pero, aún así, organismos como el Banco Mundial, consideran que la migración puede jugar un rol importante frente a los eventos naturales, en tanto, los recursos que puede movilizar a través de las remesas familiares se convierte en una forma de apoyo a los hogares, pues estas parecen aumentar después de los fenómenos naturales (World Bank 2016b, 13-16). Algunos organismos financieros internacionales, con frecuencia, otorgan financiamiento para actividades como la construcción de represas hidroeléctricas para la generación de energías y prácticas agrícolas monocultivistas como la palma africana o para la explotación de minerales.

- Los procesos migratorios (como ocurre con la migración centroamericana que se dirige hacia Estados Unidos de Norteamérica) están acompañados de innumerables riesgos durante la travesía que ponen en peligro el patrimonio, la integridad y la vida de las personas que migran. Las agresiones físicas, los secuestros, las extorsiones, la explotación sexual o los asesinatos contra personas migrantes, han sido documentados por la Comisión Interamericana de Derechos Humanos (2013), Human Rights Watch (2016) y Aministía Internacional (2010). Los riesgos durante el viaje, se ven incrementados por el endurecimiento de las políticas migratorias en los países de destino y del fuerte control migratorio en los de tránsito. Todo esto apenas parece merecer la atención de quienes solamente están interesados en resaltar los beneficios de la migración.

Aspectos como los anteriores no suelen ser discutidos por quienes ven en la migración una realidad positiva en la que todos ganan, a la vez, tienen impactos globalmente y pueden modificar los patrones migratorios a gran escala. Transformar esas realidades requiere no solo grandes acuerdos y consen- 
sos respecto del tipo de sociedades que deseamos ser como humanidad. Si bien es necesaria una ética global fundada en el respeto pleno de los Derechos Humanos, la solidaridad, la justicia y la democratización económica también urgen acuerdos tanto políticos como económicos que garanticen que las personas no tengan que abandonar sus países para buscar en otros lo que se les niega en el propio.

A escala nacional y local, también pueden verse con nitidez los impactos que este hecho tiene en la vida de las personas, de sus familias y de las organizaciones que construyen. Existen factores que contribuyen a desestructurar las relaciones familiares y causar rupturas o fragmentar el tejido social. Veamos de forma breve e introductoria los siguientes:

- La migración tiene un fuerte impacto en las familias. La partida de alguno de sus miembros, el padre, la madre o los hijos, significa muchas veces no solo la distancia física, sino la ruptura al interior del hogar. Que una persona migrante deje a la familia en el país de origen "abarata los costos de manutención, siempre más caros en Estados Unidos" (Caamaño 2010, 111). Los costos e impactos que tiene para cada uno de los miembros son distintos y así debe reconocerse.

- En contextos de expulsión migratoria, las mujeres que se quedan asumen no solo la crianza y cuido de los hijos, también las responsabilidades ligadas al hogar $y$, con frecuencia, son las responsables de atender los compromisos hipotecarios o deudas que dejó quien emigró. Además de cumplir con sus responsabilidades, son sujetas del control de los hombres (esposos) que se fueron. Caamaño (2010, 185-198) ha estudiado estas relaciones a partir de casos en Costa Rica: a las mujeres, se les restringe la salida a los lugares o a actividades públicas y se espera sumisión de parte de ellas. Rodríguez, al analizar los impactos de la migración en mujeres salvadoreñas y nicaragüenses, ha hecho notar que lejos de ser esa fuerza liberadora o emancipadora de las mujeres, como optimistamente se creyó con los primeros estudios de la migración y mujeres, reproduce y perpetúa los roles tradicionales y de similar subordinación y discriminación de las mujeres en los lugares de origen y destino $(2011,85)$.

Así las cosas, la migración puede acentuar el ejercicio de poder a partir de prácticas de control de parte de los hombres que se marcharon sobre las mujeres que se quedaron. Por otra parte, si ellas son las emigrantes, se les transfiere la responsabilidad de la destrucción del hogar, con lo cual se fortalece el rol que les asigna: guardianas del hogar.

En el caso de los niños, niñas y adolescentes, también se han documentado impactos de distinto tipo. Se dan sentimientos de ansiedad y frustración ante la partida de los padres o de alguno de ellos, así como, repercusión en el rendimiento escolar. El anhelo de la reunificación familiar es un deseo latente, el cual muchas veces les empuja a tomar la decisión de migrar en busca 
de sus padres en los países de destino. UNICEF (2016) y Sassen (2016) han realizado una recopilación de los principales peligros que viven los niños, niñas y adolescentes que migran desde Centroamérica hacia Estados Unidos. Entre estos, se resaltan los riesgos a abusos físicos, sexuales, secuestro, trata de personas e incluso la pérdida de la vida.

Los hombres también se ven afectados por la experiencia migratoria. La masculinidad es puesta en tensión a partir de los valores tradicionales de sus comunidades de origen y en las que deben de vivir en los países de destino.

La migración puede debilitar a organizaciones de base en comunidades o países expulsores. Esto se puede constatar en las comunidades de origen cuando miembros de la organización se van o, incluso, algunos de sus dirigentes toman la decisión de migrar. Esto debilita a las organizaciones en su estructura y, sobre todo, en las agendas de trabajo -cuando son reivindicativas o sus luchas tienen una orientación política- pues se sustituyen algunas de las demandas por los paliativos expresados en la forma de remesas familiares. Esto será motivo de análisis en la segunda parte del artículo. Por otra parte, no se desconoce que la migración motiva la organización de oriundos de un país o región en los países de destino; algunos suelen reunirse para llevar a cabo obras de caridad o bien social a favor de sus comunidades de origen. En la región centroamericana, el caso de los salvadoreños en Estados Unidos de Norteamérica ha sido motivo de diferentes estudios (PNUD 2005).

Sería mezquino no reconocer que la migración puede tener impactos positivos en las personas, en las familias, en las comunidades, y en los países de origen y destino. Pero de aceptarlo a mantener una postura que solamente resalta los beneficios sin reparar en los aspectos que la originan, hay una gran diferencia.

También, debe reconocerse que la migración es una realidad compleja que transforma la vida de las personas que migran, como de las comunidades de origen y de destino. Entrevistas a personas que migraron y retornaron, realizadas en el marco de la investigación que dio lugar a este artículo, evidencian cómo ellas reconocen que esta experiencia transformó completamente su vida, sus vínculos afectivos con su familia (esposas, hijos, hijas, padres y madres), sus pautas de sociabilidad (que transitaron de expresar profunda confianza en otras personas, hasta la desconfianza absoluta en otros migrantes que se aprovecharon de ellos).

Los cambios derivados de la migración también son perceptibles en las comunidades de origen. Estos van desde los procesos de despoblamiento -en algunos distritos del cantón de Pérez Zeledón, los entrevistados señalaron cómo en los últimos años era notoria la disminución en la cantidad de jóvenes a raíz de la migración-, pasando por la renovación del paisaje urbano y rural con las nuevas construcciones fruto de la recepción de remesas familiares, hasta la introducción de hábitos de consumo adquiridos en los países de destino. También se transforman las comunidades de destino, tanto a partir de la cultura, las costumbres y prácticas de las que son portadores quienes 
llegan, como por la contribución a la dinamización de la estructura demográfica doméstica (las personas migrantes suelen tener más hijos que sus pares nacionales).

Ha sido de interés, en este primer apartado, revisar algunos aspectos críticos ligados a los contextos de salida que nos permitan tener presente que no podemos olvidar la necesidad de transformar esas realidades. Ello contribuirá a que el entorno condicione cada vez menos la decisión de migrar, de manera que esta sea un hecho voluntario o deseado y menos algo forzado o impuesto. A continuación, se revisarán algunos impactos en la vida de los hombres y de una organización compuesta en su mayoría por productores agrícolas de una región de Costa Rica.

\section{Migraciones desde Costa Rica: algunos impactos, pérdidas y costos}

Las migraciones desde Costa Rica, principalmente hacia Estados Unidos de Norteamérica, no son recientes. La información censal de ese país de destino lo confirma: para 1970, había un total de 16691 costarricenses residiendo en esa nación. Para el 2010, la cantidad se había incrementado a 126 428. Si bien los emigrantes nacionales provienen de diversos cantones, los datos censales en Costa Rica muestran que hay algunos de estos con alta emigración. Por su parte, entrevistas realizadas a personas que migraron desde cantones reconocidos como expulsores (Dota, Tarrazú, León Cortés y Pérez Zeledón) ubican las primeras migraciones desde esos cantones a principios de los años sesenta del siglo pasado. Kordick-Rothe (2008) señala que, en los cantones de la zona de Los Santos, estas empezaron a ocurrir a finales de esa misma década.

Los datos del Censo de Población en Costa Rica del 2011 mostraron que había un total de 43240 hogares costarricenses con familiares residiendo en el extranjero. En términos relativos, ello representó un 3,5 \% del total de hogares en el país. De estos cantones, al menos cuatro sobresalieron por tener un porcentaje superior al promedio nacional: Pérez Zeledón con 8,16 \%; Tarrazú con $9,39 \%$; Dota con 7,95 \% y León Cortés con 7,20 \%. El trabajo de campo del proyecto de investigación del que se desprende este artículo fue desarrollado en estos cantones, debido a la importante proporción de hogares con familiares en el extranjero.

Por otra parte, a partir de un análisis de los datos censales, Brenes $(2013,7)$ identifica tres núcleos de cantones del país en los que sus habitantes tienen mayores probabilidades de emigrar. Estos son: a) la zona central de la Gran Área Metropolitana; b) la Zona de Los Santos y parte de la Zona Sur (Región Brunca); y c) los cantones centrales y del sur de la provincia de Alajuela, entre los que se destacan: Valverde Vega (Sarchí), Alfaro Ruiz (Zarcero), San Ramón, Naranjo, Palmares, Poás y Grecia. 
De estos tres núcleos, se resalta que el segundo y el tercero tienen en común una base productiva con una importante participación del sector primario (agricultura), el cual cuenta con una concentración en la producción de café, actividad que demanda de manera intensa mano de obra durante varios meses en el año. Este dato ha resultado de suma importancia para identificar, en el transcurso de la investigación -plasmada en otro artículo-, cómo dos de los tres núcleos expulsores de población costarricense han surgido de cantones que se han visto forzados a transformar su estructura socio-laboral desde las actividades agrícolas-cafetaleras a otras, principalmente, del sector terciario (servicios).

Dentro de la región centroamericana, países como Guatemala, El Salvador y Honduras han visto incrementar de manera significativa la cantidad de emigrantes, principalmente a Estados Unidos. Esta migración ha sido, en especial, de carácter económico-laboral. Además, como en los últimos años, la presencia de redes criminales, maras y pandillas ha introducido la violencia, esta se ha vuelto un poderoso factor que genera la expulsión de personas desde países. Estas realidades han hecho que los gobiernos desplieguen estrategias y acciones específicas para atender las demandas de su población migrante.

Por su parte, la atención a las migraciones en Costa Rica ha estado centrada casi exclusivamente en los nicaragüenses que llegan al país. Mientras hay un abandono a la atención de las necesidades que pueda tener la población nacional que emigra. Al respecto, pueden citarse como ejemplos: la presencia marginal de la emigración en la Ley General de Migración y Extranjería (Ley 8764) o la Política Migratoria Integral (aprobada en diciembre del año 2013); más aún, el tema está totalmente ausente en los Planes Nacionales de Desarrollo 2002-2006 de la Administración Pacheco de la Espriella, 2006-2010 de la Administración Arias Sánchez, de la Administración Chinchilla Miranda (2011-2014) y de la Administración Solís Rivera (2015-2018). En la actualidad, no hay ninguna acción de política pública dirigida a atender procesos de reintegración de personas costarricenses migrantes que retornen al país. Si bien Costa Rica no expulsa la misma cantidad de migrantes que otros países de la región, ello no justifica, de ninguna manera, la ausencia de atención estatal en el tema. Una de las pocas excepciones es la posibilidad que brindó el Tribunal Supremo de Elecciones para que, a partir del año 2014, los costarricenses que residen en el exterior pudieran ejercer el derecho al voto.

En este apartado, nos concentraremos en resaltar algunos impactos, pérdidas y costos de la experiencia migratoria en la vida de hombres que se fueron y retornaron al país. Retomamos el concepto de "costos de la migración", descrito en la parte introductoria. El interés de enfocarnos en este grupo específico surge del trabajo que se ha llevado a cabo durante varios años de apoyar la formación e investigación de una organización agraria que había tomado poca conciencia de cómo la emigración está afectando a sus miembros y al grupo como organización social. El primer paso consiste en establecer algunas pérdidas individuales identificadas por los hombres migrantes que retornaron. 
2. Se realizaron un total de siete entrevistas individuales y dos grupos focales en los cuales participaron 15 hombres, a quienes previamente se les invitó para que compartieran su experiencia de migración y retorno. Todos los participantes son adultos. Del total de entrevistados (siete) y participantes en los dos grupos focales (15), 20 se dedican a labores agrícolas. La estadía migratoria de cada uno fue de al menos un año.

\section{Pérdidas a nivel individual}

Tomando como base entrevistas individuales y comentarios obtenidos a través de dos grupos focales con hombres que tuvieron la experiencia de migrar hacia Estados Unidos y retornar a sus comunidades de origen, se identificaron algunas pérdidas, las cuales fueron señaladas de forma recurrente por los entrevistados ${ }^{2}$. Estas, según los entrevistados, pueden ser afectivas y materiales. Si bien los hombres entrevistados no lo expresaron de manera explícita, las pérdidas a las cuales se refieren podrían ser reflejo del debilitamiento de actitudes y prácticas patriarcales de ellos respecto a sus pares femeninas; esto al asumir que el patriarcado, según Lagarde (2003), es un "espacio histórico de poder masculino" que ha estado y sigue estando presente en las relaciones entre hombres y mujeres.

\section{Pérdidas afectivas}

Un primer nivel identificado por los hombres migrantes que retornaron se relaciona con pérdidas afectivas. El espacio en el que con mayor claridad se muestra es la familia y la esposa es la figura en el cual la pérdida se hace más notoria. Los entrevistados señalan la disminución o ausencia de los vínculos afectivos que los unían con esta figura. A la par de este sentimiento de pérdida, se manifiesta un reproche a sí mismos por no haber estado presente en los momentos cuando la esposa necesitaba su compañía. La enfermedad es uno de los ejemplos en los que este sentimiento se manifiesta con más intensidad. Uno de los entrevistados lo expresó de la siguiente manera:

Durante el tiempo que estuve allá, mi esposa se enfermó mucho, incluso la hospitalizaron. Yo me di cuenta después, porque mi suegra me llamó para decirme... Mi esposa nunca me dijo nada... Si hubiera sabido que ella estuvo en el hospital, seguramente me hubiera regresado, pero no me di cuenta... Yo creo que ella ha resentido mucho que yo no haya estado en esos momentos que fueron duros para ella... Yo decidí venirme porque mi suegra me llamó y me dijo: “¿Qué es más importante para usted: su familia, su esposa y sus hijos o el dinero?" Yo le pregunté a mi suegra: “¿Qué pasa?” Y ella me respondió: "Su esposa se está muriendo y usted no se ha dado cuenta. Si usted no viene, ya no la va a ver". Y era cierto, mi esposa estaba muy enferma. Tenía una depresión enorme, cuando yo llegué a la casa la vi como un palillo. 
La vi tan mal, tan mal, que me pregunté si había algo qué hacer. Me di cuenta que estaba perdiendo a mi familia y mi esposa se estaba muriendo... Si yo me hubiera quedado unos meses más, no vuelvo, porque seguro se hubiera muerto mi esposa y ya no tenía razón para volver. Estuve a punto de perder mi hogar, por suerte no se perdió, pero estuve a poquito de perderla toda... Uno se malacostumbra que todo lo resuelve con dinero. Lo llaman para contarle algún problema y uno lo primero que pregunta es “¿Cuánto es lo que necesitan?”, y no siempre lo que necesitan es dinero, es la presencia de uno acá.... el lazo de amor como que va desapareciendo poco a poco, aunque uno no lo quiera (ES).

La pérdida se pondera en términos del tiempo y de lo que se pudo hacer para acompañar un proceso de enfermedad durante la ausencia. La valoración posterior a la experiencia migratoria permite aquilatar el valor que tiene la familia para quien se fue y retornó. Esta valoración en el caso de la persona entrevistada, no se realizó durante su estadía en el país de destino, desde allá, según lo expresa, todo parecía resolverse con dinero, con el envío de remesas.

Según narra el entrevistado, no fue la propia esposa quien le comunicó su enfermedad, fue la suegra, ella planteó la pregunta que lo hizo reaccionar. En el relato, este hombre describe que no era consciente de que poco a poco estaba perdiendo a su familia, aunque tuvo la oportunidad de reconstruirla con el paso de los años.

Un caso más dramático lo vivió RV, otro de los entrevistados, que migró desde el distrito de San Pedro en Pérez Zeledón a Estados Unidos durante poco más de tres años. Viajó indocumentado por Canadá. Previamente, había acordado con su esposa que él viajaría durante no más de cuatro años para ahorrar, pues necesitaban hacerlo para comprar una parcela, ya que no tenían donde trabajar. RV es agricultor y toda su vida ha trabajado la tierra. Durante el tiempo que estuvo en los Estados Unidos, se comunicaba por carta y por teléfono con su esposa. Cuando partió, había dejado dos hijos pequeños. Al cabo de tres años, tomó la decisión de retornar, según narró: "Algo en mi corazón me decía que tenía que regresar", continúa diciendo:

Mi esposa estaba feliz de que yo regresara, pero estaba enferma, ya ella me había dicho, cuando yo estaba allá, que no se sentía bien de salud... Cuando regresé, mi es- 
posa me dijo que no se sentía bien, yo pensaba que era porque yo había regresado y habíamos pasado tres años y tres meses separados, pero no era eso... Una semana después que vine, fuimos a donde el doctor y él la mandó a hacer unos exámenes... Ella no sabía y ahí nos enteramos que tenía leucemia... Viera cómo se sintió ella cuando le dijeron lo que tenía, no lo sabía... Yo creo que mi corazón me decía que tenía que venirme a Costa Rica, porque ella estaba enferma y no sabíamos... Ella solo aguantó un mes después de que yo me vine de Estados Unidos y murió, como que me estaba esperando para despedirme... Viera que gran dolor el que sentí... Yo me sentaba solito en las noches a la orilla de la cama y decía: “¿Y ahora qué voy a hacer con estos chiquitos que casi ni me conocen? ¿Cómo los voy a sacar delante?” Y yo me sentía muy triste, porque pensaba que si yo hubiera estado aquí, tal vez hubiera podido estar más tiempo para hacer algo, para buscar tratamientos... ¿Sabe qué era duro para mí? Recordar que cuando fuimos esposos y yo estaba allá, ella me decía que su ilusión era que yo regresara para que fuéramos juntos a la playa a pasear con los niños y eso no lo pude cumplir, no pude cumplir su sueño de ir a la playa juntos, como hacen las familias normales que van a pasear... No lo pude cumplir, porque ella ya estaba enferma y vine prácticamente a enterrarla... Habíamos comprado un carrito con el dinero que yo mandaba y ella me decía: "En ese carrito, vamos a ir a la playa", y nunca pudimos ir. Ese dolor en el corazón lo llevaré siempre (RV).

La ausencia de quien migró se torna más significativa cuando hay un proceso de enfermedad de alguno de los miembros de la familia que se quedó. Esta no es compensada con remesas económicas o los bienes materiales que se 
puedan acumular como fruto del trabajo de quien se fue. La ausencia no es solo física, es también una privación afectiva tanto para los que se van como para quienes se quedan. Esto se procesa y se asume de distintas formas. El ausente puede sustituir -como lo expresaron los entrevistados- esa privación afectiva en el país de destino, consumiendo alcohol o drogas, pero también con el juego, la prostitución o con largas jornadas de trabajo. No es infrecuente que quienes se van, terminen abandonando a la familia que dejaron en su país y la sustituyan por otra.

Para quienes se quedan -especialmente las esposas-, la privación afectiva se expresa de distintas formas: concentrándose en el cuido y crianza de los hijos, haciéndose cargo de la casa o la parcela, atendiendo las responsabilidades materiales que surjan y administrando los recursos que llegan. La experiencia migratoria con frecuencia refuerza los patrones de la división sexual del trabajo. Caamaño (2010, 185-198) ha hecho notar las prácticas de control ejercidas sobre las mujeres por los hombres costarricenses que han migrado hacia Estados Unidos.

El relato de RV muestra cómo la ausencia no le permitió acompañar a su esposa en un proceso -desconocido para ambos- de enfermedad progresiva que fue acabando con la salud y la vida de ella. El entrevistado, con frecuencia, se recriminaba no haber estado ni haber tenido noticias de lo que sucedía, pues algo hubiera podido hacer, según su decir. Su reproche también se dirigía a no haber disfrutado junto a su esposa e hijos, el fruto de su trabajo en Estados Unidos. Así, expresó que el anhelo de ir a la playa a pasear "como una familia normal" quedó truncado para siempre.

Los entrevistados dejaron ver que la pérdida de la familia no abarca solamente a la esposa o pareja. Alcanza y se extiende a los hijos e hijas que se quedaron. En la relación descrita por ellos, emergen sentimientos contrapuestos. Desde los hijos, parece surgir una distancia afectiva, la cual es comprensible por el período -muchas veces prolongado- durante el cual, el padre estuvo ausente. Este alejamiento introduce y produce tensión en las relaciones. Quien regresa puede convertirse en un desconocido, sobre todo cuando los hijos crecieron estando él ausente. Uno de los entrevistados lo expresó de la siguiente forma:

Cuando regresé, mis hijos no me hacían caso. Si yo les decía algo, era como que yo le hablara a una silla, no se meneaban.... hasta hace poquito, las cosas han empezado a cambiar con mis hijos... Dejé un niño de un año y después de cuatro años que regresé, me tardé más de un año para recuperarlo, para que me reconociera como su papá, para que me diera un abrazo, esas cosas uno 
las reciente mucho, porque uno parece un desconocido o intruso que está llegando a la casa (ES).

Esta especie de rechazo experimentado por el entrevistado deja ver los retos del padre migrante que retorna: debe reconstruir las relaciones de confianza y de afecto con sus hijos. Como se observa, esto puede demorar meses e incluso años, según cada caso particular. Asimismo, el rechazo se puede asumir como una forma de debilitamiento del patriarcado asumido como ejercicio de poder masculino, según la expresión de Lagarde (2003). Por otra parte, también desde los hijos se expresan algunas resistencias a reconstruir en la cotidianidad la relación con los padres que se marcharon, sobre todo, cuando la experiencia migratoria ha sido prolongada. Un estudiante de una universidad pública, hijo de un hombre que emigró, y quien reside en el distrito de Palmares en Pérez Zeledón lo planteó de la siguiente manera:

Mi papá se fue hace 19 años, yo estaba muy pequeño y no había entrado a la escuela. Se fue a trabajar y durante ese tiempo solo ha regresado cuatro veces... Por el trabajo de él, tenemos una casa con algunas comodidades, los tres hijos estamos estudiando y no nos ha faltado nada... Él nos dice cada año que ya va a regresar. Yo cuando estaba más carajillo me hacía muchas ilusiones de que volvería, pero ya no creo que se venga... no sé si quiero que regrese, ya nos acostumbramos a vivir sin él... Hace un tiempo, me dijo que tiene un ahorro y que quiere venir a poner un negocio aquí. Él piensa que todo es igual a como lo dejó, pero ya no, todo ha cambiado... Cuando me pregunta, yo le digo que mejor se quede, que aquí le va a costar mucho, que está difícil la cosa (MS).

Según lo expresado por MS, la vida de quienes se quedaron se ha desarrollado asumiendo la ausencia del padre en lo cotidiano. Los hijos estudian, crecen, establecen relaciones con sus pares. La madre asume las tareas de cuido y crianza, mientras que el padre es solo el proveedor lejano. MS duda respecto a si desea que su padre regrese. Durante la entrevista, parecía decidido a querer convencer a su papá para que no vuelva al país. Según él, su progenitor tiene una visión romántica de la Costa Rica que dejó hace casi dos décadas, la cual ahora es distinta. Cree que su papá tendrá problemas para reintegrarse, si decide volver. Con mucha probabilidad, según lo que 
manifestó el entrevistado, la principal dificultad la tendrá en el propio hogar, pues ellos se acostumbraron a vivir sin él.

Por otro lado, en los hombres que emigraron y retornaron, parece emerger el sentimiento de que su esfuerzo no se valora o que solamente se hace en términos de ser proveedor. Uno de los entrevistados, originario de Rivas de Pérez Zeledón, afirmó que:

Allá, muchas veces no me comía cosas que deseaba, por tal de ahorrar, me aguantaba. Le digo a mi mujer que siempre quise comerme unos helados que se miraban muy ricos y por tal de ahorrar, nunca me los comí... En ese tiempo, esos helados valían 8 dólares y eso era mucho para mí... allá tuve muchas privaciones y eso que trabajaba de domingo a domingo, con dos trabajos... Mi mujer, cuando hablábamos, solo era darme quejas y decirme que no le alcanzaba, quizás ella y mis hijos pensaban que yo ganaba mucho dinero. Al principio, les enviaba cada mes, pero luego la carajilla mía fue creciendo y me llamaba para pedirme dinero, que es que esto, que es que aquello, y, claro, yo no se lo podía negar. Yo creo que querían que yo me quedara siempre, para que les estuviera mandando dinero $(A B)$.

Este relato deja ver la interpretación del migrante que retornó, en la cual se asume como proveedor, lo que, a su vez, le permite tener el control sobre la familia. Por otra parte, subyace un reclamo hacia su familia: las privaciones que tuvo no eran cabalmente valoradas por ellos.

Nótese que, dentro de los relatos y testimonios consignados hasta este momento, no se ha incluido alguno que reconozca las actitudes de dominación y control hacia las mujeres sugeridas por Caamaño (2010). Esta práctica común dentro de distintas experiencias migratorias parece invisibilizarse por quienes construyen el relato acerca de su historia como migrante. No se cree que tales ejercicios de dominación y control hacia las esposas no existan o no se lleven a cabo. Empero, el tema no fue mencionado por los entrevistados, quienes se enfocaron en señalar los costos y beneficios de la migración. La mayor concesión realizada por ellos se orientó en reconocer que la experiencia migratoria había dado como resultado que sus esposas fueran "más espabiladas" o tuvieran un mayor "empoderamiento" en los asuntos relacionados con la administración de la finca o parcela, así como en atender las responsabilidades de la casa durante su ausencia. 
¿Por qué en la construcción del relato de los hombres migrantes que retornaron no se resalta el ejercicio de poder y control que pueden ejercer o ejercen sobre sus esposas o compañeras desde el país de destino? Aunque no es motivo de este escrito, se debe dar al menos una explicación. Un primer aspecto a considerar es el entorno cultural patriarcal en el cual acontece la experiencia migratoria en el país de origen. El patriarcado como categoría y práctica es asumido, según el significado propuesto por Lagarde $(2003,91)$, como un: "espacio histórico de poder masculino... conformado por varios ejes: el antagonismo de género, la asignación de espacios de vida que le son destinados a partir de su condición y de su situación genérica, el fenómeno cultural del machismo basado en el poder masculino..." (2003, 91). En este entorno, la mujer cumple un rol y es el de la reproducción, que alterna y complementa con el cuido y resguardo de la familia. Su papel es subalterno tanto en el ámbito privado (la familia) como en el social-comunitario o público.

Este marco refuerza la división sexual del trabajo y que en entornos capitalistas asigna a las mujeres un tipo de trabajo no mercantilizado, el cual no se relaciona con el precio, sino que ideológicamente es aceptado como una función natural. Es lo que "tiene que ver con la atención y el cuidado mutuo, con determinados aspectos del trabajo que aportan satisfacción y bienestar individual, familiar o social que en el mercado no encuentran equivalente. Se trata de una noción del valor que contribuye a generar una riqueza que, en lugar de vincularse a crecimiento, se asocia a bienestar" (Carosio 2009, 239 y Lagarde 2003, 119-133).

Dicho de otra forma, en la construcción del relato migratorio, lo referido al ejercicio del poder y control que ejercen los hombres migrantes sobre las mujeres no desaparece, simplemente está ahí, pero se asume como algo que forma parte de los roles tradicionalmente asignados. No se cuestiona porque se asume como "natural".

Un segundo aspecto, derivado del anterior, es que se refuerza la asignación de roles para el hombre y para la mujer. El hombre no solo se asume a sí mismo con el destino de ser el elegido para ir a trabajar, viajar y desplazarse, sino que también considera que a la distancia, debe mantener el dominio y control del hogar dejado en su país. A pesar de esto, las mujeres que se quedan garantizan, lo llamado por Sassen (2003), la feminización de la supervivencia, la cual no es ni más ni menos que asegurar el sustento y la búsqueda del bienestar aún en contextos de profundas carencias. 
Así, en lo cotidiano, para los entrevistados, no parece haber tensión respecto a los roles que se asignan a lo largo de la experiencia migratoria. El ejercicio del poder sobre las mujeres y los hijos que se quedan parece ser solo una extensión de su responsabilidad de hombres y de padres, la cual cumplen con proveer desde la distancia.

\section{Pérdidas materiales}

A las pérdidas afectivas que señalan los hombres migrantes que han retornado, deben adicionarse las materiales que surgen en los distintos momentos de la experiencia migratoria. Las condiciones de salida pueden ser un primer factor que influya en pérdidas patrimoniales no solo de quien se va, sino, solidariamente, de su familia. Aunque no se tiene un dato preciso acerca de cuántos migrantes costarricenses cuyo destino es Estados Unidos lo hacen con visa de ingreso, las entrevistas permitieron verificar que hubo tanto migrantes irregulares (ingresaron evadiendo controles migratorios) como regulares (viajaron directamente a Estados Unidos con visa de turista). Esta distinción es necesario realizarla, pues quienes viajan de forma irregular, deben contratar "los servicios" de un coyote. Para el 2016, en Pérez Zeledón, un coyote podría cobrar entre U\$9 000 y U $\$ 10000^{3}$.

3. Datos proporcionados por

Quienes se ven forzados a migrar y no tienen recursos propios o ahorros para solventar los gastos de viaje, deben endeudarse. Aunque esto es menos frecuente que en años pasados, aún existen prestamistas para este fin. A cambio de dinero, exigen una garantía que usualmente es una propiedad. El préstamo hipotecario es también un "servicio" ofrecido por algunos bancos y cooperativas de la región. Un funcionario bancario entrevistado indicó que si bien hace unos años, la cantidad de propiedades "rematadas" públicamente por la entidad en la cual labora por falta de pago era grande, en los últimos años, esta ha disminuido. El remate de tierras o casas de familias de emigrantes por falta de pago no solo ha dejado a estas sin casa, sino que otros han tenido la posibilidad de adquirirlas a precios muy bajos. Uno de los entrevistados comentó lo siguiente:

Cuando yo me fui, tuve que asumir un préstamo de tres millones y medio. Era para pagar al coyote y para llevar un dinerito por cualquier cosa... El viaje fue por México y de ahí nos fuimos a Montreal, y luego entramos... Yo estuve en la cárcel y la deuda creció... Había pensado que, apenas llegando, empezaría a trabajar y mandaría dinero para ir pagando la deuda, pero se complicó por el tiempo que estuve en la cárcel... También había que pagar un abogado y las llamadas que eran caras... también había que pagar los intereses... De los tres millones y medio 
que presté al principio, la jarana fue subiendo hasta que llegó a diez millones... Eso era mucho dinero y había que pagarlo, me tardé casi dos años para pagarla, pero la pagué (RV).

Lo relatado por RV deja ver los altos costos que tuvo la travesía. Pierde el migrante, y ganan los coyotes y prestamistas, estos últimos son quienes más se benefician. Lo anterior, junto al mercado de las remesas, los préstamos, y el comercio de bienes y servicios asociados a la migración, crea una economía migratoria, en la cual, los que se van deben pagar caro cada bien o servicio requerido.

Al costo del préstamo ha de sumarse el riesgo de perder la propiedad o la casa que se puso a responder por la hipoteca. En el distrito de Rivas de Pérez Zeledón, se entrevistó a un joven, sobrino de emigrantes, que narró lo siguiente:

Aquí mis abuelos no quieren saber nada de la gente que se va, ellos han sufrido mucho por eso... Mis dos tíos se fueron hace unos años... Uno de ellos le pidió a mi abuelo que le ayudara hipotecando la casa y mi abuelo, aunque no quería hacerlo, lo ayudó... Mi tío le dijo que en cuanto llegara, les iba a mandar dinero para pagar la deuda de la casa... Como un año mandó dinero, pero no mandaba mucho... Al final, le quitaron la casa a mis abuelos y están alquilando ahí... perdieron la casa en la que habían vivido toda su vida y mis tíos ya no vinieron. Ahora mi papá es el que tiene que ayudarles con el alquiler porque solos no pueden (ST).

Hay, al menos, una doble pérdida en este caso. La primera es la de los vínculos con la familia: los hijos no volvieron más. También, está la del principal patrimonio con el que contaban los padres: la deuda fue saldada, el prestamista hizo efectiva la hipoteca y se quedó con la casa.

La expectativa de tener mejores condiciones de vida con el envío de las remesas familiares o de ahorrar para retornar no siempre se logra alcanzar. Para muchos hogares, la migración puede resultar beneficiosa por distintos aspectos que son conocidos (el incremento de los ingresos del hogar y las posibilidades de mejora en las condiciones de vida o la reunificación familiar). Para otras, en cambio, esta experiencia es la única posibilidad de sobrevivir o 
de perder lo poco que se tenía. En el caso del cantón de Pérez Zeledón, hay una alta dependencia de la migración y de las remesas familiares. De acuerdo con 201 entrevistas a hogares con familiares migrantes, un $67 \%$ de estos depende del envío mensual, quincenal o semanal de remesas para su subsistencia. Por otra parte, aproximadamente un $10 \%$ de lo recibido lo destinan al pago de hipotecas o deudas.

Cuando se resaltan los potenciales beneficios derivados de la migración, con frecuencia, se pasan por alto las pérdidas que esta experiencia lleva implícita; hemos mencionado las afectivas, a través de las rupturas familiares, y las materiales, las cuales pueden profundizar y hacer más dolorosas las primeras. En el apartado siguiente, se hará referencia a las pérdidas de los vínculos con la comunidad tomando como referencia la experiencia de una organización campesina.

\section{Pérdida de los vínculos con la comunidad}

La experiencia migratoria de cada persona puede tener distintos arreglos, los cuales se fortalecen, suspenden o extinguen con su comunidad de origen. La larga historia de mexicanos que han migrado hacia Estados Unidos desde principios del siglo anterior ha dado lugar a que comunidades de zacatecanos instalados en Los Ángeles -formando incluso federaciones de clubes de zacatecanos- mantengan fuertes vínculos con sus comunidades de origen y contribuyan a distintas causas o a resolver necesidades comunitarias (García Zamora 2001, 2009).

En otra dirección, también es conocido que uno de los impactos de la migración es el deterioro de los vínculos con la comunidad de origen. Esto puede observarse cuando existen factores -como la violencia- que condicionan y hacen forzosa la salida del lugar, como se observa actualmente en Guatemala, Honduras y El Salvador (CIDH 2013). También es cierto que la migración puede debilitar los lazos con organizaciones comunitarias de las cuales formó parte quien se marchó. Así, surge lo siguiente: ¿en qué medida la migración puede ser un factor que mine el tejido de una organización social? La respuesta ha de valorar no solo el tipo de organización social, sus reivindicaciones, el tamaño, sino también las características y tipo de membresía que la conforme.

Una organización social puede ser un grupo constituido jurídicamente o no, el cual actúa a partir de valores, principios, causas, aspiraciones o intereses comunes. En ese sentido, una organización social jurídicamente constituida puede ser una cooperativa, una asociación de desarrollo, un sindicato o una asociación gremial de productores. En cambio, la que no está constituida jurídicamente puede tomar la forma de un colectivo organizado, el cual reivindica derechos humanos, demandas económicas y sociales, o rechaza la expansión monocultivista, por citar algunos ejemplos. La distinción entre ambas se establece no en los ámbitos temáticos que les interesan o las mueven, sino en la constitución jurídica que poseen. 
Esta distinción operativa es de utilidad para responder a la pregunta planteada en el sentido siguiente: la migración puede debilitar a una organización jurídicamente constituida tanto en la cantidad de miembros que posee, como -y lo más importante- en la identidad, las luchas y reivindicaciones que la organización lleve a cabo. Para acercarnos a responder de manera precisa, se analizará el impacto de la migración en una organización agraria constituida desde hace poco más de cuarenta años en Pérez Zeledón, uno de los principales cantones expulsores de población migrante en Costa Rica.

Si bien es cierto existen otro tipo de organizaciones sociales como las cooperativas, donde media un interés asociativo y económico de sus miembros, estas suelen incorporar a personas que llevan a cabo distintas actividades, con lo cual, se diluye naturalmente un interés sectorial común, comprensible por la diversidad de actores que la integran.

En cambio, una organización agraria permite identificar con claridad intereses comunes articulados en torno a reivindicaciones productivas o políticas definidas colectivamente; estas son reforzadas, a la vez, por un sentido de pertenencia e identidad que surge de compartir la actividad y el trabajo agrícola. Más aún, como se verá, en el caso de la organización agraria que se tuvo como referencia, un significativo porcentaje de sus miembros tienen familiares migrantes, muchos fueron obligados a esta situación por la desmejora de las condiciones del sector agrícola costarricense en los últimos años.

La organización agraria a la que se hará referencia es la Unión de Productores Independientes y Actividades Varias (UPIAV). Esta se encuentra presente en los cantones de Pérez Zeledón (donde se concentra la mayoría de sus miembros), Buenos Aires, Quepos y Osa de la provincia de Puntarenas. Para el 2016, cuenta con una membresía cercana a los 8650 afiliados. Durán Barrantes (2006) nos ofrece una descripción del contexto en el que surgió la UPIAV:

En 1971 se constituyó la Unión de Productores Independientes y Actividades Varias (UPIAV), grupo que inició buscando reivindicaciones por tierras $y$, poco más tarde sumaba a su plataforma original la lucha contra las irregularidades que se producian en los beneficios de café. Dichos objetivos le hicieron un movimiento sumamente dinámico que rápidamente condujo a la movilización de los campesinos, al mismo tiempo que ejercían presión y planteaban fuertes críticas contra la Beneficiadora Neverman, La Meseta y la misma Cooperezeledón R.L. Por su carácter beligerante y la forma de encontrar soluciones a los problemas del campesina regional, la UPIAV se dife- 
renció diametralmente de los fundamentos socio-empresariales propuestos por el cooperativismo, con lo que en poco tiempo se convertiría en un frente de confrontación con tendencia a un pensamiento de izquierda que sumaba adeptos con mucha facilidad (Durán Barrantes 2006, 87).

Durante poco más de cuatro décadas, UPIAV se ha consolidado como la principal organización reivindicativa agraria del cantón de Pérez Zeledón y una de las más importantes a nivel nacional. Su historia está ligada a las demandas del sector agropecuario de la Región Brunca y es continuamente interlocutora frente a actores públicos en temas de producción, acceso a crédito y comercialización de productos agrícolas de los cantones donde está presente. La organización lo plantea en los siguientes términos: "Nuestro principal objetivo es en favor de los pequeños y medianos productores, en conjunto con organizaciones hemos emprendido luchas para mejorar las necesidades de caminos, puentes, transporte, servicios médicos, técnicos, comercialización, entre otros"4. Las demandas citadas expresan un tipo de reivindicación política que procura resolver las necesidades de los pequeños productores de la zona. Según uno de los miembros de la Junta Directiva:

La UPIAV ha sido la organización más fuerte de la zona, hemos estado en distintas luchas, no solo en Pérez Zeledón, sino a nivel nacional... ¡Qué va!, las condiciones de nosotros los agricultores han empeorado mucho. Los precios del café se han venido abajo, por eso, muchos de los miembros de la organización han tenido que dejar la agricultura porque no la ven... es difícil mantenerse en esto, es mucho sacrificio, mucho trabajo que no se reconoce (JR, participante en grupo focal, con la Junta Directiva de la organización).

Lo expresado por JR remite a varios aspectos. El primero tiene que ver con la participación de la organización en distintas luchas a nivel nacional, regional y cantonal. Durante el grupo focal, los miembros de la Junta Directiva mencionaron distintas batallas de reivindicación político-sectorial en las que la organización ha participado: la asignación de fondos para proyectos de reconversión productiva, la aprobación del sistema de banca para el desarrollo, el establecimiento de convenios para el aseguramiento social de trabajadores agrícolas pertenecientes a organizaciones campesinas, la ampliación del 
hospital regional y el cobro diferenciado del impuesto de bienes inmuebles para tierras de uso agrícola, por citar algunos ejemplos. La participación de UPIAV en las luchas canaliza las demandas de pequeños productores a través de los líderes que han sido elegidos. Esto requiere de legitimidad y representatividad, las cuales surgen del apoyo de una membresía conformada por agricultores de la zona. En otras palabras, la organización es el vehículo político que traslada las reivindicaciones del grupo.

El segundo aspecto citado por JR nos remite a las condiciones adversas que ha enfrentado el sector agrícola costarricense. Con datos del Banco Central de Costa Rica, se observa que en 1992 (en saldos a diciembre), el crédito al sector agrícola otorgado por el sistema bancario nacional (público y privado), expresado en dólares corrientes fue de U\$192,6 millones, en tanto que para ese mismo año, el crédito para consumo alcanzó los U\$161,4 millones. Para el año 2015 (en saldos a diciembre), el mismo crédito del sistema bancario nacional destinado al primer sector agrícola fue de U\$ 617,2 millones, mientras que para consumo, el crédito alcanzó los U\$ 5.692,8 millones. Dicho con otras palabras, el crédito para las actividades agrícolas se multiplicó por tres, mientras que el otro por treinta y cinco en un período de veintitrés años. El comportamiento del crédito en el sector agrícola es solo una variable del cambio en las políticas de fomento productivo adoptadas por el Estado costarricense, dentro de lo que Vargas (2016) ha llamado el "Proyecto Histórico Neoliberal" acontecido entre los años de 1984-2015.

Por otra parte, a la disminución del crédito al sector agropecuario costarricense, debe agregarse la volatilidad de los precios del café, principal producto producido por los miembros de UPIAV. Esto los ha afectado. Un integrante de la Directiva lo expresa en los siguientes términos:

Los precios del café han estado malos desde hace muchos años, algunas veces levanta, pero casi siempre los precios van a la baja. Eso ha afectado mucho acá en el cantón... mucha gente ha dejado del todo el café y han vendido, otros se han ido para el Norte... allá les va mejor trabajando de peones en la construcción que aquí pulseándola todo el año y Dios guarde que caiga alguna plaga como la roya, eso sí que le arruina a uno, hay que podar las matas como pasó hace un par de años (RCh.)

Esta persona introduce una relación que se observa con claridad en el cantón de Pérez Zeledón: en la emigración participan, de manera activa, personas que durante años han estado vinculadas a actividades agrícolas, especialmente a la producción de café. Agrega este entrevistado: 
Mucha gente que tenía café acá en Pérez Zeledón se ha ido... también miembros de UPIAV se han ido bastantes, nosotros lo hemos notado, hay filiales nuestras en las que llega la esposa o los hijos mes a mes a pagar el seguro, pero uno sabe que están allá y no dejan la organización por el beneficio del Seguro que les damos (RCh.).

Como lo indica este líder de la organización, ellos saben que muchos de sus miembros se han ido y que, a pesar de haber migrado hacia Estados Unidos, mantienen activa su membresía. Esto porque les garantiza poder seguir pagando el seguro social a través del convenio que tienen con la Caja Costarricense del Seguro Social, lo cual les asegura la atención a la salud de los integrantes de la familia que se quedaron en el país.

La organización ha resentido la partida de muchos miembros que participaban como responsables o líderes en las filiales que UPIAV tiene en diferentes distritos de la región. Como resultado, ha habido una menor actividad de las filiales a las cuales pertenecían quienes emigraron. Entre octubre y diciembre del 2015, se aplicó una encuesta a 2298 miembros de la organización. De ellos, $424(18,45 \%)$ indicaron que tienen padre, madre, hijos o hermanos en Estados Unidos.

Acá es necesario volver a la interrogante ¿puede la migración ser un factor que debilite a una organización como UPIAV? La respuesta es sí. Lo hace no solo en la cantidad de miembros que posee, los cuales son su principal recurso. Este debilitamiento se observa en varios planos. El primero es la pérdida de fuerza de la organización: deja de convertirse en un vehículo político que canaliza las demandas y reivindicaciones de sus miembros, los cuales forman parte del sector agrícola en los cantones donde tiene presencia. Esta pérdida de fuerza acontece en un contexto en el que la migración se convierte en una forzosa alternativa para una parte de quienes históricamente han estado vinculados a actividades agrarias y deben desplazarse hacia otras actividades. Tal fenómeno puede influir en el desgaste del carácter político de la organización. Los miembros de la organización que emigran no se desvinculan completamente, mantienen una relación que les es de utilidad a través del pago de la membresía, lo que les abre la posibilidad de no perder el acceso al Seguro Social.

Un segundo plano donde se observa el impacto es en la disminución de actividades que se llevan a cabo en las seccionales de la organización, pues algunos de los encargados de las bases han migrado. Si bien hay presencia formal de esta organización en distintos distritos del cantón, se ve debilitada por la ausencia de líderes.

Un tercer plano en el cual la migración debilita a la entidad se observa en que muchos de quienes se van abandonan definitivamente la actividad agrícola para trasladarse a realizar otras labores, como construcción, la reparación y 
limpieza de casas, el transporte o el trabajo en restaurantes en el país de destino. Con ello, la identidad hacia la agricultura se pierde y, a su vez, la vinculación con la organización se fragmenta.

La migración mina el tejido social al convertirse en la respuesta forzada que encuentran aquellos cuyo proyecto de vida ha estado vinculado con la tierra, la agricultura y la vida del campo, según las entrevistas realizadas en el cantón de Pérez Zeledón. Con esto, no se afirma que esta sea la realidad de todos los emigrantes que salen de Costa Rica, pero sí de muchos que han dejado el cantón y a la vez han formado parte de UPIAV.

¿En qué sentido se debilita la identidad de la organización a partir de la experiencia migratoria? Al migrar forzadamente, y abandonar la tierra y la agricultura, muchos de sus miembros -algunos de los cuales han sido destacados líderes en las filiales- pueden transmitir de manera implícita un mensaje en el cual expresan el fracaso de esta actividad, por lo tanto, de la organización que la reivindica. La migración, en este contexto, se convierte en un salvavidas artificial. Esto lo expresaron reiteradamente los entrevistados.

Esa transición que propicia el emigrar convierte a muchos agricultores en fuerza de trabajo exportable, lo cuales no necesariamente irán a cultivar la tierra al país de destino. Con esto, no se idealiza la agricultura ni al agricultor, solo se verifica un cambio de labor. La identidad de la organización se debilita, pues los miembros que se van, probablemente, no vuelvan nunca más y, con ello, la migración la drena poco a poco y debilita tanto sus luchas como sus reivindicaciones.

Si retomamos el planteamiento de Harvey (2004), según el cual, los excedentes de capital y de fuerza de trabajo existentes en un territorio "que no pueden ser absorbidos internamente deben ser enviados a otro lugar a fin de encontrar un nuevo terreno para su realización rentable para no ser devaluados", podríamos afirmar que quienes han estado ligados a actividades agrícolas en los cantones de estudio, serían ese "excedente" que se envía a otro lugar, con lo cual, se actualiza una forma de incorporación de las economías periféricas a la economía global.

\section{Conclusiones}

A nivel global, nada parece indicar que los procesos migratorios se detendrán. Por el contrario, en los próximos años, este fenómeno acrecentará, si no se revierten los procesos de acumulación y concentración patrimonial, así como los efectos del cambio climático. En la medida en que subsistan conflictos armados en distintos lugares del orbe, los desplazamientos humanos serán un drama al cual asistiremos continuamente.

Debe decirse que los procesos de globalización y de concentración capitalista han mostrado sus limitaciones a pesar de los esfuerzos de sus partidarios, los países ricos y, en especial, los de los organismos financieros multilatera- 
les, como el Banco Mundial y el Fondo Monetario Internacional o de la Organización Mundial del Comercio, por promover y sacar partido de sus bonanzas. Ni la mayor apertura a la economía internacional ni la desregulación de los mercados o las privatizaciones han contribuido eficazmente a reducir una de las principales tragedias humanas contemporáneas: la pobreza de millones de personas a nivel mundial.

Erradicar la pobreza y revertir la concentración de la riqueza tanto a nivel global como al interior de los países exige acuerdos eficaces que permitan dar un giro inmediato a una tendencia que profundiza odiosas desigualdades sociales.

Existen contradicciones que deben corregirse. Rodrik $(2014,345)$ ha señalado que:

Gracias a los esfuerzos de Estados Unidos y otros países ricos, las barreras al comercio de bienes, los servicios financieros y los flujos de inversión han registrado los niveles históricos más bajos, pero el único mercado en donde las naciones pobres tienen algo que vender en abundancia, el mercado de los servicios laborales, no se ha visto afectado en lo más mínimo por esta tendencia liberalizadora.

Adicionalmente, no solo se restringe la migración con el blindaje de fronteras, sino que se fortalece una coraza a través de legislaciones que la sancionan cuando ocurre de manera irregular.

Rodrik (2014) ha sugerido que una medida concreta es establecer sistemas que concedan permisos laborales temporales entre países ricos y países pobres hasta por un " $3 \%$ de la fuerza de trabajo de los países ricos". Esto podría generar "un ingreso anual de 200,000 mil millones de dólares para los ciudadanos de las naciones en vías de desarrollo, mucho más de lo que se espera que produzca la actual agenda de comercio de la OMC" $(2014,346)$. Un argumento similar ha sido sostenido por Piketty $(2014,603)$, quien ha propuesto que una forma de redistribuir la riqueza mundial es a través de la inmigración, pues al dejar que el trabajo (humano) se desplace a lugares con salarios más altos, habría una más directa redistribución del capital global.

Con la migración está en juego la vida de millones de personas que deben desplazarse, al ser expulsadas de sus países. Ello requiere un diálogo multilateral y acuerdos técnicos como el establecimiento de sistemas de permisos de trabajo, según sugiere Rodrik (2014), o convenios para realizar mayor inversión en regiones con altos niveles de pobreza. También, son necesarios los compromisos ético-políticos: que establezcan prioridades acerca de hacia dónde dirigimos la inversión pública social. En una región empobrecida como 
Centroamérica, en el marco de los mecanismos de integración, debe valorarse de manera regional, por ejemplo, la disminución progresiva de los presupuestos militares hasta alcanzar un recorte del $20 \%$, para invertirlos en educación, salud, vivienda, cultura y recreación.

Precisamente en Centroamérica, el incremento de la violencia en Guatemala, Honduras y El Salvador ha dado lugar a un éxodo de personas, por el cual, los más afectados son niñas, niños y adolescentes, muchos de ellos, migrantes sin compañía. Esto lanza nuevos retos a tales países.

Justamente en esta pequeña zona, el discurso acerca de los pretendidos beneficios de la migración ha encontrado tierra fértil. En la primera parte de este artículo, hemos discutido la supuesta bondad de la migración y de una de sus expresiones más visibles: las remesas. Empero, estos argumentos resultan endebles por el punto de partida desde el cual se elaboran: renuncian a discutir el entorno y las razones profundas o estructurales que causan la migración. En cambio, priorizan explicarla a partir de decisiones individuales, como si estas no estuviesen condicionadas y determinadas por los contextos en los cuales "tal decisión se toma". Tampoco consideran los riesgos que asumen las personas durante la travesía migratoria, en particular a partir del refuerzo de la securitización de las fronteras, como está ocurriendo en los últimos años.

Frente a los argumentos triunfalistas, se han contrapuesto otros más realistas, los cuales cuestionan la validez de los primeros. En general, debe decirse que los países expulsores pierden su principal factor: las personas. También, se señaló que deben moderarse las expectativas acerca de los alcances que pueden tener las remesas familiares, pues mientras ayudan -como al modo de un remedio- a aliviar transitoriamente la insuficiencia de ingresos de los hogares, constituyen, con frecuencia, solamente un recurso transitorio y artificial.

Entrevistas realizadas con hombres agricultores, quienes han emigrado y retornado de Estados Unidos, permitieron establecer algunos costos y pérdidas identificados a partir de la experiencia migratoria. La díada costos-beneficios de la experiencia migratoria fue un marco interpretativo sugerido por las personas entrevistadas, para explicar el valor que tuvo este hecho en la vida de ellos. Hubo consenso en señalar que la migración permite -si se llega con bien al destino- trabajar y ahorrar algunos recursos para ser invertidos en el país de origen. Sin embargo, lo anterior tiene costos: el principal es la alta posibilidad de la pérdida de la familia, de los vínculos afectivos con la esposa y con los hijos. Este aspecto fue resaltado con suma intensidad por las personas entrevistadas. Algunos afirmaron que perderla no se compensa con todo el dinero que se pueda ganar ni con todos los bienes materiales que se puedan acumular.

Dado que se entrevistó a hombres migrantes cuyo trabajo ha sido en labores agrícolas y forman parte de una organización agraria, se pudo verificar que la migración tiene un impacto negativo en esta. Principalmente, porque disminuye la membresía de participantes, con lo cual, a la vez que debilita las reivin- 
dicaciones políticas o los intereses del sector, afecta la identidad de la organización al percibirse un cierto fracaso de la agricultura.

Un tema ausente en la identificación de los costos de la migración por parte de los entrevistados fue la relación de dominación y ejercicio de poder que ejercen los hombres migrantes respecto de sus esposas o compañeras. Desde una matriz patriarcal, ello podría ser explicado por el rol que se autoasignan ellos como proveedores y jefes de familia. Aún a la distancia, buscan mantener y reproducir el control en el hogar. Ahondar en este análisis es una tarea pendiente para una futura investigación.

\section{Bibliografía}

Amir, Samin. 2010. Escritos para la transición. Vicepresidencia del Estado Plurinacional de Bolivia. La Paz: edición PDF.

Amnistía Internacional. 2010. Víctimas invisibles. Migrantes en movimiento en México. Madrid, España: Amnistía Internacional.

Bakker, Matt. 2007. «El discurso de las remesas como impulsoras del desarrollo y la agencia colectiva del migrante colectivo». Revista Migración y Desarrollo, 9: 45-72. Disponible en http://www.redalyc.org/pdf/660/66000903.pdf

Banco Central de Costa Rica. 2015. Aspectos socioeconómicos de las remesas familiares 2014. División Económica, Área de Encuestas Económicas Banco Central. Recuperado de http://www.bccr.fi.cr/publicaciones/politica_cambiaria_sector_externo/As pectos_Socioeconomicos_de las_Remesas_Familiares_2014.pdf

Banco Interamericano de Desarrollo. 2005. Remesas de inmigrantes. Moneda de cambio económico y social. Recuperado de http://www.rrojasdatabank.info/iadbremit/remesas05.pdf

Bonilla Leal, Salvador. 2016. Migración internacional, remesas e inclusión financiera. El caso de México. Centro de Estudios Monetarios Latinoamericanos (CEMLA). México. Recuperado dehttp://www.cemla.org/PDF/remesaseinclusion/2016-08-migracionremesas-inclusion-mexico.pdf 
Brenes, Gilbert. 2013. «Análisis estadístico-demográfico de las bases de datos de ingresos y egresos por puestos fronterizos de la Dirección General de Migración y Extranjería». Informe de Investigación. Centro Centroamericano de Población. Universidad de Costa Rica.

Caamaño, Carmen. 2010. Entre arriba y abajo. La experiencia transnacional de la migración costarricense hacia Estados Unidos. San José: Editorial de la Universidad de Costa Rica.

Carosio, Alba. 2009. Feminismo latinoamericano: imperativo ético para la emancipación. En Género y globalización. Buenos Aires, Argentina: CLACSO. Recuperado de http://biblioteca.clacso.edu.ar/clacso/gt/20140611041611/11caro.pdf

Céspedes, Oswald, Ricardo Monge y Juan Carlos Vargas. 2010. Análisis de un corredor de remesas norte-sur en los contextos norte-sur y sur-sur: Estados Unidos-Costa Rica. Washington: FOMIN-BID.

Comisión Interamericana de Derechos Humanos. 2013. Derechos humanos de los migrantes y otras personas en el contexto de la movilidad humana en México. Washington, D.C.: CIDH. Recuperado de http://www.oas.org/es/cidh/migrantes/docs/pdf/Informe-MigrantesMexico-2013.pdf

Delgado Wise, Raúl, Humberto Márquez y Héctor Rodríguez. 2009. «Seis tesis para desmitificar el nexo entre migración y desarrollo». Revista Migración y Desarrollo (12): 27-52. Acceso el 20 de octubre de 2015. http://rimd.reduaz.mx/revista/rev12/2.pdf

De Cambra, Jordi. 2009. Desarrollo y subdesarrollo del concepto de desarrollo: Elementos para una reconceptualización. Recuperado de http://www.unida.org.ar/Bibliografia/documentos/Modulo_Basico/Libro El_Resignifizcado_del_Desarrollo_MBC/03_Desarrollo_y_Subdesarroll o_del_Concepto_de_Desarrollo_Elementos_para_una_Reconceptualiz acion.doc 
Durán Barrantes, Norman Dimas. 2006. «Evolución de la producción azucarera en el distrito de El General, Pérez Zeledón, entre la segunda mitad del siglo XIX y la década de 1970». Revista de Historia (53-54): 63-98.

García Zamora, Rodolfo. 2009. «El programa iniciativa ciudadana 3x1 de remesas colectivas en México». En: Migración a Estados Unidos: remesas, autoempleo e informalidad laboral, coordinado por Arroyo Jesús, Berumen Salvador, 337-360. México: Universidad de Guadalajara-SEGOB.

García Zamora, Rodolfo. 2001. «Migración internacional, remesas y proyectos sociales: una propuesta de desarrollo regional para Zacatecas». En: Sin Fronteras-CEPAL-UAZ: Transferencias y uso de remesas: proyectos productivos y de ahorro, ,225-254. México: Sin Fronteras-CEPAL-UAZ.

Gatica López, Gustavo. 2013. «Desarrollo y migraciones internacionales. Notas para la discusión». Revista Rupturas 3(2): 140-169. Acceso 21 de octubre 2015. http://dialnet.unirioja.es/servlet/articulo? codigo $=4888211$

Gudynas, Eduardo. 2012. «Debates sobre el desarrollo y sus alternativas en América Latina. Una breve guía heterodoxa». En: Más allá del desarrollo, compilado por Miriam Lang y Dunia Mokrati, compiladoras, 225-254. Quito, Ecuador: Ediciones Abya Yala.

Harvey, David. 2004. «El nuevo imperialismo: acumulación por desposesión». Disponible en http://biblioteca.clacso.edu.ar/clacso/se/20130702120830/harvey.pdf

Human Rights Watch. 2016. Puertas cerradas. El fracaso de México en la protección de niños refugiados y migrantes en América Central. Recuperado de https://www.hrw.org/es/report/2016/03/31/puertascerradas/el-fracaso-de-mexico-en-la-proteccion-de-ninos-refugiados-y 
Kordick-Rothe, Carmen Rebeca. 2008. «Primeros emigrantes de Costa Rica a Nueva York y Nueva Jersey». En El mito roto: inmigración y emigración en Costa Rica, por Carlos Sandoval García. San José, Costa Rica: Editorial de la Universidad de Costa Rica.

Mansur Dias, Guilherme. 2014. «Migração, segurança e governabilidade migratória. O papel dos Organismos Internacionais». Revista Crítica y Emancipación $\quad \mathrm{VI}(11)$ : Disponible enl http://biblioteca.clacso.edu.ar/clacso/se/20140701050349/CyEN11.pdf

Lagarde y de los Ríos, Marcela. 2003. Los cautiverios de las mujeres: madres, monjas, putas, presas y locas. Segunda reimpresión. México: UNAM.

Programa de las Naciones Unidas para el Desarrollo. 2009. Informe sobre Desarrollo Humano 2009. Superando barreras: movilidad y desarrollo humanos. México: PNUD. Mundi-Prensa.

Programa de las Naciones Unidas para el Desarrollo. 2005. Informa sobre Desarrollo Humano El Salvador 2005. Una mirada al nuevo nosotros. El impacto de las migraciones. El Salvador: PNUD.

Organización Internacional para las Migraciones. 2015. Informe sobre las migraciones en el mundo 2015. Los migrantes y las ciudades: nuevas colaboraciones para gestionar la movilidad. Ginebra. OIM. Recuperado de http://publications.iom.int/system/files/wmr2015_sp.pdf

Orozco, Manuel y Julia Yansura. 2013. Migración y Desarrollo en América Central: Percepciones, Políticas y Nuevas Oportunidades. Working paper. Washington: Inter-American Dialogue.

Orozco, Manuel. 2012. América Latina y el Caribe: desarrollo, migración y remesas. Buenos Aires, Argentina: FLACSO/Inter-American Dialogue/ Teseo.

Pécoud, Antoine. 2015. «Remesas desde la perspectiva de los organismos internacionales: construcción de un desafío y elaboración de una 
agenda política internacional». Revista Migración y Desarrollo 13(25): . Acceso el http://estudiosdeldesarrollo.net/revista/rev25/2.pdf

Piketty, Thomas. 2014. El capital en el siglo XXI. México: Fondo de Cultura Económica.

Ratha, Dilip. y Sonia Plaza. 2011. Harnessing Diasporas. Recuperado de http://www.imf.org/external/pubs/ft/fandd/2011/09/pdf/ratha.pdf

Rodríguez, Olga. 2011. Migración, mujeres y vivienda. La Conquista, Nicaragua y Texistepeque, El Salvador. San Salvador: PNUD/UCA.

Rodrik, Dani. 2014. Una economía, muchas recetas. La globalización, las instituciones y el crecimiento económico. México: Fondo de Cultura Económica.

Sassen, Saskia. 2016. «Tres migraciones emergentes: un cambio de época». Revista Internacional de Derechos Humanos 13(23): 29-42. Acceso el http://sur.conectas.org/wp-content/uploads/2016/09/2-sur-23-espanholsaskia-sassen.pdf

Sassen, Saskia. 2003. Contrageografías de la globalización. Género y ciudadanía en los circuitos transfronterizos. Traficantes de Sueños. Recuperado el de https://www.traficantes.net/sites/default/files/pdfs/Contrageografias \%20de\%20la\%20globalizaci\%C3\%B3n-TdS.pdf

Stiglitz, Joseph y Andrew Charlton. 2007. Comercio justo para todos. Madrid: Taurus.

Vargas Solís, Luis Paulino. 2016. «Apuntes de coyuntura: El Proyecto Histórico Neoliberal en Costa Rica (1984-2015): Devenir histórico y crisis» Revista Rupturas, 6(1): 147-162. Disponible en línea: http://investiga.uned.ac.cr/revistas/index.php/rupturas/article/view/116 7

World Bank. 2016a. Migration and Remittances. Factbook 2016. (3a . ed.) World Bank Group. Recuperado de 
https://openknowledge.worldbank.org/bitstream/handle/10986/23743/978146 4803192.pdf?sequence $=3 \&$ isAllowed $=y$

World Bank. 2016b. Migration and Remittances. Recent Developments and Outlook. Migration and Development Brief 26. World Bank Group. Recuperado de http://pubdocs.worldbank.org/en/661301460400427908/MigrationandDe velopmentBrief26.pdf 